\title{
O ENFERMEIRO E O CUIDAR DA CRIANÇA COM CÂNCER SEM POSSIBILIDADE DE CURA ATUAL
}

\author{
The nurse and the care provided for child with cancer without the possibility of cure at \\ the moment. \\ El enfermero y el cuidar del niño con cáncer sin posibilidad de cura actual
}

Ana Claudia Moreira Monteiro ${ }^{1}$

Benedita Maria Rêgo Deusdará Rodrigues²

Sandra Teixeira de Araújo Pacheco ${ }^{3}$

\section{RESUMO}

0 estudo objetivou analisar compreensivamente o cuidado do enfermeiro à criança hospitalizada portadora de doença oncológica fora de possibilidade de cura atual. A fenomenologia sociológica de Alfred Schutz fundamentou a análise possibilitando a apreensão desse cuidado como uma conduta humana. Os sujeitos foram 12 enfermeiros do setor de internação pediátrica de um hospital público federal especializado em oncologia, do município do Rio de Janeiro, cuja aprovação no CEP deu-se com o Registro $n^{\circ} 43 /$ 11. As falas foram captadas no período de junho a julho de 2011, com a entrevista fenomenológica guiada pela questão orientadora: 0 que você tem em vista quando cuida de crianças fora de possibilidade de cura atual? $\mathrm{Na}$ análise compreensiva surgiram duas categorias: confor to e minimização da dor. A partir dessas ações direciona-se o cuidar para o familiar ali presente, com o intuito de apoiá-lo, proporcionando atitudes de carinho, afeto e respeito.

Palavras-chave: Enfermagem oncológica. Cuidado da criança. Cuidados paliativos.

\begin{abstract}
The study aimed at analyzing comprehensively the nurse care for hospitalized children suffering from oncological diseases with no chance of cure at the moment. The sociological phenomenology from Alfred Schutz's supported the analysis allowing the apprehension of this care as a human behavior. The subjects were 12 nurses from the pediatric admission center of a federal public hospital specialized in oncology, at the Rio de Janeiro district whose approval in the CEP was registered under the number \# 43/11. The statements were taken from June to July 2011 , following the phenomenological interview guided by the guidance question: What do you have in mind when caring for children with no chance of healing today? In the comprehensive analysis two categories emerged: comfort and minimize the pain. From these actions directs the care for the family present there, in order to support it, providing attitudes of tenderness, affection and respect.
\end{abstract}

Keywords: Oncologic Nursing. Child Care. Hospice Care
Resumen

El estudio objetivó analizar comprehensivamente el cuidado del enfermero al niño hospitalizado portador de enfermedad oncológica sin posibilidad de cura actual. La fenomenología sociológica de Alfred Schutz fundamentó el análisis, posibilitando la aprehensión de ese cuidado como una conducta humana. Los sujetos fueron 12 enfermeros del sector de internación pediátrica de un hospital público federal especializado en oncología, en el municipio de Rio de Janeiro, cuya aprobación en CEP se hace con Registro N. 43/11. Los diálogos fueron captados en el período de junio a julio de 2011, con la entrevista fenomenológica guiada por la cuestión orientadora: ¿Qué usted tiene en vista cuando cuida de niños sin posibilidad de cura actual? En el análisis comprehensivo surgieron dos categorías: confort y minimización del dolor. A partir de esas acciones, se dirige el cuidar para el familiar presente con el objetivo de apoyarlo, proporcionando actitudes de cariño, afecto y respecto.

Palabras clave: Enfermería oncológica. Cuidado del Niño. Cuidados paliativos.

\footnotetext{
${ }^{1}$ Professora Substituta do Departamento de Enfermagem Materno-infantil da Faculdade de Enfermagem da Universidade do Estado do Rio de Janeiro. Mestre em Enfermagem pelo Programa de Pós-Graduação, Mestrado, da Faculdade de Enfermagem/UERJ. Rio de Janeiro - RJ. Brasil. E-mail: anaburguesa@hotmail.com; ²Professora Titular do Departamento de Enfermagem Materno-infantil da Faculdade de Enfermagem da Universidade do Estado do Rio de Janeiro. Procientista/UERJ/FAPERJ. Pesquisadora CNPq Nível 2. Rio de Janeiro - RJ. Brasil. E-mail: benedeusdara@yahoo.com.br; ${ }^{3}$ Professora Adjunta do Departamento de Enfermagem Materno-infantil da Faculdade de Enfermagem da Universidade do Estado do Rio de Janeiro. Rio de Janeiro - RJ. Brasil. E-mail: stapacheco@yahoo.com.br
} 


\section{INTRODUÇÃO}

No Brasil, segundo dados do Ministério da Saúde, o câncer foi considerado a quinta causa de óbito em pessoas de 1 a 19 anos. $^{1}$

Em 2008, foram diagnosticados 9.890 novos casos de câncer infantil no Brasil. ${ }^{2}$ Nas estimativas de 2012, esse número aumentará para 11.530 casos em crianças e adolescentes ${ }^{3}$.

Do ponto de vista clínico, os tumores pediátricos apresentam menores períodos de latência; em geral, crescem rapidamente e são mais invasivos; porém respondem melhor ao tratamento e são considerados de bom prognóstico. ${ }^{4}$

Durante o tratamento oncológico, algumas crianças podem não responder à terapêutica e, após se esgotarem todos os recursos oferecidos para o tratamento, passam a ser consideradas como crianças as quais não foi possível curar. ${ }^{5}$

Entretanto, cabe ressaltar que isso não significa dizer que não elas necessitam de cuidados dos profissionais de saúde; mesmo que não possam ser curadas, ainda se pode fazer muita coisa, do ponto de vista da manutenção da dignidade do ser humano-criança, contribuindo, assim, para um cuidado centrado nas suas necessidades. É considerado fora de possibilidade de cura atual o paciente para o qual foram esgotados todos os recursos atuais conhecidos para sua cura. A incorporação dessa concepção de cuidar possibilitou o desenvolvimento do cuidado paliativo. $^{6}$

Para a Organização Mundial da Saúde, os cuidados paliativos são ativos e totais para os pacientes cuja doença não responde a um tratamento curativo e têm o objetivo de alcançar a melhor qualidade de vida para estes e suas famílias. ${ }^{6}$

Em pediatria, o cuidado paliativo é definido como um programa organizado, voltado para a criança com vida limitada devido a uma doença atualmente incurável. Este se torna eficaz com o controle dos sintomas e quando são fornecidos apoio psicológico e espiritual para o paciente e suporte para a família na tomada de decisões. ${ }^{1}$

Portanto, o enfermeiro que atua em cuidados paliativos deve desempenhá-los a partir de uma visão humanística, em que apesar da impossibilidade da cura, a sua relação com o paciente não deve deixar de acontecer, o que poderá trazer benefícios para ambos. ${ }^{7}$

Porém, o cuidar de crianças fora de possibilidade de cura em oncologia é bastante difícil, visto que o enfermeiro, muitas vezes, não consegue lidar com a morte e o morrer como uma possibilidade do fim do ciclo da vida. ${ }^{7}$ Sendo assim, enquanto a criança se encontra em um momento de maior necessidade de cuidado e atenção, os profissionais nem sempre estão preparados para compartilhar esse momento tão difícil, demonstrando que prestar assistência à criança com câncer sob cuidados paliativos é um processo de sofrimento e um misto de emoções para o profissional. ${ }^{8}$

A partir dessas considerações iniciais, traçamos como questão nor teadora do estudo: como os enfermeiros cuidam das crianças hospitalizadas portadoras de doença oncológica fora de possibilidade de cura atual?

0 objeto de estudo foi o cuidado do enfermeiro à criança hospitalizada portadora de doença oncológica fora de possibilidade de cura atual, e o objetivo foi analisar compreensivamente 0 cuidado do enfermeiro à criança hospitalizada portadora de doença oncológica fora de possibilidade de cura atual.

\section{REFERENCIAL TEÓRICO}

Ao buscar a compreensão do cuidado realizado pelo enfermeiro à criança hospitalizada, em tratamento oncológico fora de possibilidade de cura atual, como uma ação social, desenvolvemos esse estudo com o apoio da fenomenologia sociológica de Alfred Schutz por possibilitar a apreensão da ação desse cuidar como uma conduta humana, em um processo contínuo a partir de um projeto pré-concebido. ${ }^{9}$

Para Schutz ${ }^{9}$, a ação social acontece a partir da compreensão do contexto da ação do homem, inserida socialmente e relacionada ao seu mundo e ao mundo do outro. Ação social é a conduta entre duas ou mais pessoas, com intenção prévia. É uma ação projetada pelo ator de maneira consciente que possui um significado subjetivo que se respalda no passado, no presente ou no futuro. ${ }^{10}$

Portanto, Schutz ${ }^{\text {9:103 }}$ refere que "o caráter intencional e todas as nossas ações necessariamente envolvem uma clara diferença entre os atos de pensar, lembrar ou temer e os objetos aos quais esses atos se referem".

A fenomenologia sociológica de Alfred Schutz possibilita a compreensão da ação social como forma vivida ou experienciada pelo enfermeiro no ato de cuidar que não se desvincula de sua história e, consequentemente, de seus motivos. Dessa forma, as motivações que podem indicar para o futuro são definidas como os "motivos para" do ponto de vista do ator, já os "motivos porquê" se referem às suas experiências passadas. ${ }^{9}$

Assim sendo, o enfermeiro, ao desenvolver sua ação de cuidar de crianças hospitalizadas em tratamento oncológico fora de possibilidade de cura atual, no dia a dia profissional, lança mão de suas vivências, ou seja, de sua bagagem de conhecimentos para agir de uma dada maneira.

Cada pessoa no mundo vivido age de modo peculiar pautada na sua bagagem de conhecimentos que lhe é própria. ${ }^{10}$

Esse mundo vivido é o mundo no qual você cresceu, viveu, teve suas experiências, significa o mundo inter subjetivo que existia antes do seu nascimento, que é experienciado e interpretado pelos outros, os predecessores, como mundo organizado. ${ }^{9}$

Todas as interpretações desse mundo são baseadas em um estoque prévio de experiências vivenciadas anteriormente ou transmitidas por nossos pais ou mestres, antes mesmo de existirmos. Essas interpretações estão sob a forma de "conhecimento à mão" que nos servem de referência. Esse 
estoque de conhecimento, que se constitui na situação biográfica de cada um, pertence ao mundo em que vivemos, e que nos faz movimentar no sentido de desempenhar determinadas ações. ${ }^{9}$

Desse modo, a compreensão das coisas no mundo se dá como um típico, em que as estruturas similares das coisas experienciadas anteriormente abrem um horizonte que se refere às futuras experiências do mesmo tipo a serem experimentadas pelos sujeitos. ${ }^{9} 0$ típico, para Schutz, está sempre em si mesmo pelo ponto de vista do intérprete e variável de acordo com seus interesses e problemas. ${ }^{11}$

Esse típico ocorre através da captação subjetiva dos significados contidos nas vivências, expressos nas falas dos entrevistados, e cuja interpretação é realizada pelo pesquisador a partir das intenções do sujeito do estudo. ${ }^{11}$

Nesse contexto, a intersubjetividade é uma questão fundamental para a existência humana, caracterizada pela relação com o outro, em que se desenvolve a ação social, por meio da troca de experiências no mundo. Esse mundo da vida diária é um universo de significados para nós, onde compreendemos os outros e somos compreendidos por eles. ${ }^{9}$

Portanto, é importante, ao buscar a compreensão do cuidado do enfermeiro à criança hospitalizada portadora de doença oncológica fora de possibilidade de cura atual, dar voz a esse profissional que lida cotidianamente com essa criança na perspectiva da captação de um modo de cuidar que lhe é peculiar e intersubjetivo.

\section{METODOLOGIA}

0 estudo foi desenvolvido nas enfermarias de oncologia e hematologia do setor de internação pediátrica de um hospital público federal especializado em oncologia, localizado no município do Rio de Janeiro. Trata-se de uma instituição de referência em oncologia que estabelece políticas juntamente com os Ministérios da Saúde e de Ciência e Tecnologia na atenção oncológica nacional, com atividades de prevenção, controle e tratamento do câncer. Essa instituição se faz presente no cenário nacional pelas pesquisas que desenvolve, apoiando a formação de recursos humanos com a titulação profissional em cursos de pós-graduação multiprofissional em nível de residência, mestrado e doutorado.?

Participaram do estudo 12 enfermeiros que atenderam ao critério de inclusão, ou seja, que realizam cuidados diretos à criança hospitalizada em tratamento oncológico fora de possibilidade de cura atual, que atuam com essa clientela há mais de um ano e que apresentaram interesse em participar desta pesquisa.

Para atender aos princípios éticos propostos para a realização da pesquisa com seres humanos, o projeto foi encaminhado ao Comitê de Ética e Pesquisa da instituição onde foi desenvolvida a pesquisa, sendo aprovado para sua realização com o Parecer $n^{0}$ 043/11. 0 anonimato dos sujeitos foi garantido com a utilização de um pseudônimo com o nome de flor de sua preferência, e todos foram esclarecidos quanto ao sigilo das informações coletadas, bem como ao direito à desistência de sua participação em qualquer fase da pesquisa. Após a leitura do Termo de Consentimento Livre e Esclarecido em voz alta juntamente com o sujeito da pesquisa e realizados os devidos esclarecimentos, foi solicitada a assinatura deste termo, que foi datado e assinado por cada um dos participantes.

0 hospital em questão foi escolhido por ser referência nacional em oncologia e que muito tem contribuído para inovações na assistência, pesquisa e qualificação profissional nessa área.

A captação das falas deu-se com a entrevista fenomenológica que se preocupa com o espaço do cliente e seu tempo, buscando captar a sua subjetividade ou sua maneira de vivenciar o mundo, pela sua forma de significar o mundo expressando seu comportamento, e sua maneira de se posicionar diante das situações. ${ }^{11}$

A entrevista fenomenológica se dá em um encontro existencial por meio de uma interação face a face que se constitui uma aproximação e empatia entre duas pessoas, em uma relação eu e tu causada intencionalmente com o objetivo de captar as vivências e experiências vividas em seu cotidiano para desvelar os fenômenos. ${ }^{12}$

Para a realização das entrevistas, foi utilizado um roteiro com a seguinte questão orientadora: Quando você cuida de uma criança fora de possibilidade de cura, o que você tem em vista? 0 agendamento de data e horário foi previamente estabelecido com os sujeitos conforme suas disponibilidades. Os encontros foram realizados em lugar reservado que foi acordado com os entrevistados, de modo que não houve interferência externa.

As entrevistas foram registradas em mp3 para que não se perdesse nenhum conteúdo das falas e para que a autora e os entrevistados pudessem estabelecer uma relação mais direta e empática possível. Após a sua realização, foram transcritas para posterior análise.

A seguir, as várias leituras das entrevistas propiciaram a apreensão do que houve de comum no conteúdo das falas dos diferentes enfermeiros participantes do estudo, captando, assim, as categorias que emergiram da ação de cuidar do enfermeiro à criança hospitalizada portadora de doença oncológica fora de possibilidades de cura atual, sem pré-julgamentos ou ideias pré-concebidas.

A partir das falas dos sujeitos do estudo, foi realizada leitura cuidadosa e atenta, buscando o que havia de comum entre elas para a construção das categorias, que possibilitaram analisar compreensivamente o cuidar dos enfermeiros à criança hospitalizada portadora de doença oncológica e fora de possibilidade de cura atual.

Nesse sentido, Minayo ${ }^{13: 59}$ refere que "no processo de análise é fundamental valorizar o material de campo, sua peculiaridade e especificidade, evitando ao máximo juízo de valor por parte do investigador". 
$\mathrm{Na}$ fenomenologia sociológica de Alfred Schutz, as categorias constituem-se a partir do que emerge da fala do entrevistado, cuja intencionalidade da ação se dá através dos significados aí contidos, mostrando-se como um típico. ${ }^{11}$

\section{RESULTADOS E DISCUSSÃO}

As categorias concretas do vivido que emergiram das falas dos sujeitos da pesquisa foram "conforto" e "minimização da dor", apresentadas e analisadas a seguir, evidenciando o que esses enfermeiros têm em vista ao cuidar da criança hospitalizada portadora de doença oncológica e fora de possibilidade de cura atual.

Os enfermeiros entrevistados, ao realizarem o cuidado à criança portadora de doença oncológica e fora de possibilidade de cura atual, enfatizaram nessa ação de cuidar a necessidade de confortar esta criança diante do seu estado de adoecimento.

Eu tento me comunicar com ele, tento passar carinho pra ele, mas também não procuro mostrar aquele ar de pena, mas sim, ele é um paciente que está precisando ser tratado [...] dar um conforto, que pelo menos é o melhor pra ele. Eu acho que nesse momento, você tem que dar um apoio ao familiar, e dar um conforto para o paciente, eu acho que eles ficam bem, eles precisam de um conforto, às vezes precisam mais do conforto do que de uma morfina subcutânea [...]. (Rosa Vermelha)

A gente tenta deixar à criança o mais confortável possível, pra não sentir dor, a gente visualiza esse lado todo [...]. No momento, acho que não temos muito que fazer, além de deixar a criança confortável e sem dor, o mais importante [...]. (Hortência)

O essencial é tornar a vida dessa criança o mais confortável pra ela, pra que ela possa ter esses dias sendo criança, porque elas são crianças, $e$ não pode ser tirado isso por causa de uma doença [...]. Se está fora de possibilidade de cura, não vamos deixar morrer [...] e fazer com que ele fique o mais confortável possível [...] devemos fazer com que ele se sinta bem, fazer com que ele brinque da maneira dele, se ele não puder, colocar um vídeo, qualquer coisa pra que ele se distraia, $e$ não fique só na cama [...]. (Girassol)

Nesses relatos, os enfermeiros ao cuidarem das crianças portadoras de doença oncológica e fora de possibilidade de cura atual, preocupam-se em dar conforto quando falam da promoção de um cuidado por meio da realização de atitudes que envolvem a família para realizar melhor a ação de cuidar.

Nessa intenção de cuidar surgem aspectos importantes para o indivíduo, promovendo o alívio da dor e o conforto através da palavra, restabelecendo condições de saúde e doação de amor, colocando-se no lugar do outro e compreendendo seu problema e seus sentimentos. ${ }^{14}$

Esse cuidar reflete uma preocupação com o outro e estabelece vínculos de carinho e afeto, promovendo manifestações de apoio e compreensão para a criança e sua família, for talecendo seus laços ${ }^{14}$.

É importante salientar que, no cuidado paliativo, a utilização de medidas de suporte e conforto para o alivio do sofrimento, em virtude do avanço da doença, devem ser priorizadas visando o bem-estar dessa criança e seus familiares. ${ }^{1}$

São estratégias de atenção da equipe que implica compromisso de oferecer um cuidado integral para melhorar a qualidade de vida da criança e dos seus familiares, abordando os problemas psicológicos, sociais e espirituais de ambos ${ }^{15,17,18}$, destacando ações interativas que se baseiam na relação de respeito e valorização do ser cuidado, buscando promover sistematicamente o que há de saudável para proporcionar o conforto. ${ }^{8,16,17}$

Os enfermeiros entrevistados expressaram a importância de promover ações para minimizar a dor, avaliando e proporcionando o bem-estar para esta clientela, tentando sempre minimizar o sofrimento, realizando um cuidado individualizado e direcionado para cada criança.

Eu faço os remédios, para não ter dor, pra não ter sofrimento [...]. Eu chamo ele, viro, vou fazer isso e vai doer, a tia está aqui com você, calma, não fica assim, não, você tá com dor? Olha pra mim, tenta apertar a minha mão, eu tento trabalhar com ele, da mesma forma, como se ele estivesse numa crise de asma, numa crise de dor, entendeu? (Rosa Vermelha)

Eu já vi quadro de criança com dor, e a mãe não queria que fizesse analgesia, porque não queria que a criança dormisse. O medo dela era: se ele dormir, ele não vai voltar, mas ao mesmo tempo, estava num quadro tão desesperador que eu tive que chamar o plantão, porque a criança precisava descansar, ela estava num sofrimento de dar dó, e a mãe não queria deixar fazer analgesia não [...]. (Hortência)

Que ele possa não ter dor, que ele possa até mesmo brincar, porque tem muitos pacientes fora de possibilidade de cura, mas eles conseguem brincar, entende? [...] 0 que a gente faz é proporcionar a medicação dentro do horário, diminuir a dor, fazer 
uma analgesia que elimine essa dor, ou se não elimina, que atenue essa dor, promover um quarto alegre pra essa criança, dar alguma interatividade pra que ele possa fazer, porque criança com dor, se estiver brincando, ela esquece a dor, então você tem que promover isso, não trancar ele no quarto com a mãe. (Girassol)

A dor é considerada um dos mais persistentes sintomas do câncer disseminado. 0 controle da dor é considerado um princípio básico para a qualidade de vida, mas em crianças 0 tratamento da dor é bastante crítico, em virtude da dificuldade de avaliar a dimensão da dor nessa faixa etária. ${ }^{1}$

Apesar dessa dificuldade, o cuidado realizado por esses enfermeiros é centrado em procedimentos para minimizar a dor e o sofrimento, característicos dessa fase da doença, o que os deixa bastante sensibilizados com a sua intensidade, buscando medidas para melhorá-la, sempre, na etapa que precede a cada procedimento.

Ficou também evidenciada, nas falas dos entrevistados, a impor tância do apoio a essa família que se encontra tão abalada no momento da internação de sua criança.

Assim, ao cuidarem de uma criança portadora de doença oncológica e fora de possibilidade de cura atual, os enfermeiros também cuidam dos familiares, por meio de uma conversa, um abraço, um ombro, ações que possibilitam consolo para 0 sofrimento por eles vivenciado. Alguns desses profissionais revelaram que, ao terem em vista o cuidar dessa família, o fazem escutando, conhecendo seus problemas, tranquilizando-os, estando junto, para amenizar aqueles momentos caracterizados por dores e medos decorrentes do processo de agravamento do quadro clínico e morte. ${ }^{5}$

Essas famílias permanecem na enfermaria em todos os momentos, e essa presença mostra a necessidade de cuidados não só para a criança, mas também para a família, por meio de apoio e atenção dos profissionais da equipe. ${ }^{18}$

Os enfermeiros preocupam-se, prioritariamente, em reduzir a dor, que é característica da doença oncológica. Essa ação constitui-se em uma conduta humana como um processo contínuo para cuidar dessas crianças a partir de um projeto préconcebido para o qual eles lançam mão dos conhecimentos adquiridos e tradicionalmente utilizados em cuidados paliativos. A ação desses enfermeiros proporcionando conforto e minimizando a dor dessas crianças se dá como uma ação social e, como destaca Schutz ${ }^{9}$, ocorre a partir da ação desses enfermeiros no mundo social, ou seja, a instituição aqui caracterizada como o cenário do estudo.

0 enfermeiro ao exercer o cuidar desvela uma conduta humana que lhe é própria no cuidado com o outro, desenvolve uma ação social baseada na compreensão do contexto familiar em que a criança fora de possibilidade de cura está inserida, buscando se aproximar dos familiares para confortá-los, visando o confor to do outro em uma relação de solidariedade.

\section{CONCLUSÃO}

Ao cuidar de criança com doença oncológica fora de possibilidade de cura atual, o enfermeiro realiza uma ação intencional, possibilitando uma assistência voltada para o ser humano-criança, cujas ações estão centradas em suas necessidades, a partir das experiências vivenciadas no contexto da hospitalização.

Então, tendo em vista 0 atendimento da criança em cuidado paliativo, o enfermeiro realiza um cuidado que se inicia com o tratamento, compreendendo sua importância na promoção de uma assistência de qualidade.

Cabe ressaltar que o confor to é um modo de cuidar do enfermeiro que está presente na assistência prestada à criança fora de possibilidade de cura atual, focalizado na proteção, na solicitude, na escuta, no restabelecimento das suas forças, principalmente em momento de desespero diante de um desfecho inevitável, deixando esta clientela especial confortável mesmo sem estar saudável.

Desse modo, o cuidado prescritivo surge como uma possibilidade proposta para o agir profissional, proporcionando o alívio dos sintomas da dor e do sofrimento causados por uma doença tão avassaladora até mesmo no seu tratamento.

Esse cuidado demanda tempo, atenção, sensibilidade, solidariedade e disponibilidade para atender às necessidades da criança.

Além disso, ao dar voz a esses enfermeiros, o estudo permitiu captar que, ao cuidarem de uma criança fora de possibilidade de cura atual, percebem que o lidar com a finitude de um ser que está começando a viver é também um momento doloroso e de difícil compreensão.

Assim, o diagnóstico de uma criança fora de possibilidade de cura atual coloca o profissional diante do paradoxo, da interrupção da linha natural da vida. Entende que a trajetória de vida deve seguir do nascimento às demais fases, ou seja, crescer, adolescer, se tornar adulto e envelhecer, para só depois culminar no morrer.

Também foi possível evidenciar que o seu cuidar é fortemente direcionado para o familiar ali presente, com o intuito de apoiá-lo nesse momento especial de adoecimento de sua criança

\section{REFERÊNCIAS}

1.Camargo B, Kurashima A. Cuidados paliativos em oncologia pediátrica. São Paulo: Lemar ; 2007.

2.Instituto Nacional de Câncer - INCA . Estimativa 2008 - Incidência de Câncer no Brasil. [citado 2008 out 01]. Disponível em: http:// www.inca.gov.br. 
3.Instituto Nacional de Câncer - INCA. Estimativa 2012 - Incidência de Câncer no Brasil. [citado 2012 jul 06]. Disponível em: http:// www.inca.gov.br

4.Instituto Nacional do Câncer - INCA. Diagnóstico precoce do câncer na criança e no adolescente. Rio de Janeiro; 2009.

5.Carneiro DMS, Souza IEO, Paula CC. Cotidiano de mães-acompanhantesde-filhos que foram a óbito: contribuições para a enfermagem oncológica. Esc Anna Nery. 2009; 13(4): 757-62.

6.Ayoub AC, Fontes ALC, Silva MAA, Alves NRC, Gigliotte PS, Boaventura Y. Planejando o cuidar na enfermagem oncológica. São Paulo: Lemar; 2000.

7.Lopes VF, Silva JLL, Andrade M. A percepção de profissionais de enfermagem sobre cuidados paliativos ao cliente oncológico pediátrico fora de possibilidade de cura: um estudo na abordagem fenomenológica das relações humanas. Online Braz J Nurs. 2007 abr; 6(3).

8.Avanci BS, Carolindo FM, Góes FGB, Netto NPC. Cuidados paliativos à criança oncológica na situação do viver/morrer: a ótica do cuidar em enfermagem. Esc Anna Nery. 2009; 13(4): 708-16.

9.Schutz A. Collected papers I: the problem of social reality. Netherlands: Martinus Nijhoff; 1962.

10.Wagner H. Sobre fenomenologia e relações sociais/ Alfred Schütz. Petrópolis (RJ): Vozes; 2012.

11.Capalbo C. Fenomenologia e ciências sociais. São Paulo: Idéias e Letras; 1998.

12.Carvalho AS. Metodologia da entrevista. Rio de Janeiro: Agir; 1987.

13. Minayo MCS. Los conceptos estructurantes de la investigación cualitativa. Salud Coletiva. 2010; 6(3): 251-61.

14.Ciuffo LL, Rodrigues BMRD, Cunha JM. 0 enfermeiro na atenção à criança com suspeita de abuso sexual: uma abordagem fenomenológica. Online Braz J Nurs. 2009; 8(3)

15.Bernadá M, Dall'Orso P, Fernández G, Le Pera V, González E, Bellora R, et al. Abordaje del niño con una enfermedad pasible de cuidados paliativos Arch Pediatr Urug. 2010; 81(4): 239-47.

16.Instituto Nacional de Câncer-INCA. Ações de enfermagem para o controle do câncer: uma proposta de integração ensino-serviço. $3^{\mathrm{a}}$ ed. Rio de Janeiro; 2008.

17.Santos MCL, Pagliuca LMF, Fernandes AFC. Cuidados paliativos ao portador de câncer: reflexões sob o olhar de Paterson e Zderad. Rev Latino-Am Enfermagem. 2007 out; 2(2): 10-6.

18.Foster TL, Lafond DA, Reggio C, Hinds PS. Pediatric palliative care in childhood cancer nursing: from diagnosis to cure or end of life. Seminars in Oncology Nursing. 2010 Nov; 26(4): 205-21. 